\title{
Idiopathic thrombocytopenic purpura
}

\author{
P H B Bolton-Maggs
}

\begin{abstract}
Idiopathic thrombocytopenic purpura in children usually a self limiting disorder. It may follow a viral infection or immunisation and is caused by an inappropriate response of the immune system. About $20-30 \%$ of children will fail to remit over six months (chronic idiopathic thrombocytopenic purpura). This is more likely in older children, especially girls. The disease is reviewed with reference to diagnosis, investigation, and management options.

(Arch Dis Child 2000;83:220-222)
\end{abstract}

Keywords: idiopathic thrombocytopenic purpura; diagnosis; treatment

Idiopathic thrombocytopenic purpura (ITP) in children is usually a self limiting disorder presenting most commonly with a short history of purpura and bruising in children of either sex between the ages of 2 and 10 years of age. The incidence is similar to that of acute leukaemia, at about 4 per 100000 children per year. ${ }^{1}$ It may follow a viral infection or immunisation and is caused by an inappropriate response of the immune system. Autoantibodies against platelet surface glycoproteins (particularly IIb/IIIa) can commonly be detected (60-70\%), but are of no prognostic significance and this is not a useful diagnostic test. $^{2}$

\section{Diagnosis}

A clear history of acute onset of purpura and/or bruising in an otherwise well child, together with careful examination of child and blood film is essential to exclude other diagnoses. Acute leukaemia rarely presents with a low platelet count alone, but aplastic anaemia (or rarely, myelodysplastic syndromes) may. Congenital thrombocytopenias may be missed because they are forgotten. In Bernard-Soulier syndrome the bleeding is often more impressive than the platelet count would suggest (for example, significant bleeding with a platelet count of $30 \times 10^{9} / 1$ ). In Wiskott-Aldrich syndrome the immune deficiency and eczema may not be prominent in the early years of life, but the platelets are characteristically smaller than normal in contrast to the large platelets seen in ITP. Another congenital disorder, which may present with bleeding in infancy and mistakenly diagnosed as ITP, is the uncommon type IIb von Willebrand's disease, where the abnormal von Willebrand factor causes platelet aggregation and thrombocytopenia. ${ }^{3}$ The child should be carefully examined to exclude congenital abnormalities that would suggest the isolated throm- bocytopenia might be the first clue to Fanconi's anaemia. In older children particularly, and those who go on to have a chronic course, one should think carefully about a wider autoimmune disorder, and look for signs and symptoms suggestive of systemic lupus or antiphospholipid syndrome. Children with haemorrhagic varicella and thrombocytopenia should be reviewed cautiously because of the rare but life threatening association with acquired protein $\mathrm{S}$ deficiency and microvascular thrombosis. ${ }^{4}$

\section{Investigation}

Is a bone marrow examination necessary? Certainly it should be done in the presence of any doubt about the diagnosis, ${ }^{56}$ but in the typical case the consensus is probably not. ${ }^{7}$ Some argue that leukaemia never presents with thrombocytopenia alone, but not all hospitals are experienced with examination of paediatric films; a number of respondents to the national audit had seen children - at least in the pastwith acute leukaemia who had received steroids for "ITP" before the correct diagnosis was made, this single agent treatment possibly jeopardising their long term survival. It is probably for these reasons that in the UK audit, ${ }^{8}$ and in the American survey, ${ }^{9}$ a marrow examination is likely to be performed before steroids are given. Particular caution should be taken with infants with Down's syndrome in whom thrombocytopenia may herald the development of megakaryoblastic leukaemia. ${ }^{10}$

\section{Management options}

Many doctors find the low platelet count frightening, but most children remit spontaneously within six to eight weeks and have only cutaneous or mild bleeding (clinically "mild" $\mathrm{ITP}^{8}$ ). There is no clear benefit in admission to hospital of children with acute ITP and cutaneous manifestations alone, although the majority are admitted-perhaps for the doctor's benefit. The busy paediatric wards are probably more hazardous than the home environment. Parents will usually be guided by the advice they are given. Most have no views on low platelet counts until given them by the doctor's words and body language. Written information about the condition, sensible advice (avoidance of contact sports, attendance at hospital in the face of accidents) and a contact name and number are usually sufficient- such as those used for other patients with bleeding disorder (haemophiliacs).

Treatment to raise the platelet count, even when profoundly low $\left(<10 \times 10^{9} / 1\right)$, is not always required. The few platelets function more efficiently. Serious bleeding is rare in ITP in contrast to severe thrombocytopenia associ- 
ated with marrow failure syndromes. Intracranial haemorrhage $(\mathrm{ICH})$ is extremely rare; only 54 cases can be found in the literature, half occurring more than four weeks from diagnosis, and 15 at more than six months. The incidence in the first week is probably $0.1-0.2 \%$, but rises to about $1 \%$ of those with counts of less than 20 after six to twelve months from diagnosis. ${ }^{1} \mathrm{ICH}$ has occurred in children on treatment, ${ }^{11}$ and is not always fatal. ${ }^{12}$

When treatment is required, options include oral steroids, intravenous immunoglobulin (IVIG), and lately, anti-D for patients who are rhesus D positive. All these treatments are associated with potentially serious side effects, and it is vital to carefully consider the balance of risks- "primum non nocere" (first of all do no harm). ${ }^{13}$ IVIG raises the platelet count rapidly (usually within 48 hours) and is therefore the treatment of choice for the rare serious haemorrhage (clinically "severe" ITP). Although IVIG is popular, up to $75 \%$ of children have side effects such as headache and fever. More seriously, some have developed meningeal irritation or transient hemiplegia. IVIG is a pooled blood product with the consequent worry about viral transmission. Although HIV transmission has not been reported, it is clear that there have been hepatitis $\mathrm{C}$ transmissions with disastrous results. IVIG should not therefore be given without clear clinical indications, other than the low count alone. Although traditionally given at a dosage of $0.4 \mathrm{~g} / \mathrm{kg}$ daily for five days, it is effective (more convenient and cheaper) at a lower dose of $0.8 \mathrm{~g} / \mathrm{kg}$ as a single dose $\mathrm{e}^{14}{ }^{15}$ or 0.25 to $0.5 \mathrm{~g} / \mathrm{kg}$ for two days; these lower doses are associated with fewer side effects. ${ }^{16}$ Steroids are usually given at a dose of 1-2 $\mathrm{mg} / \mathrm{kg} /$ day for up to two weeks; more recently a pilot study has shown that shorter courses at higher dose $(4 \mathrm{mg} / \mathrm{kg} /$ day for four days) may raise the count as fast as with IVIG. ${ }^{17}$ This may be the most attractive option in the child with significant or troublesome symptoms (clinically moderate rather than severe). Anti-D is effective in $\mathrm{Rh}$ positive children and has the advantage of being a rapid single injection. ${ }^{14}$ However, significant haemolysis and fall in haemoglobin requiring blood transfusion has recently been reported after this treatment. ${ }^{18}$ The problem with all these treatments is that they do not treat the underlying disorder, only the low count, so that relapse is common. The temptation to continue long term oral steroids must be resisted because of the serious potential side effects which may be worse than the disease.

Splenectomy is rarely required (two large paediatric haematology centres in the UK have between them performed less than five splenectomies for ITP in the past 10 years) and should only be considered for significant bleeding, with failure to respond to medical treatment, and more than six months from diagnosis, i.e. when the ITP is chronic. ${ }^{19}$ The failure rate after splenectomy is about $25-30 \%$, and is probably more (up to $60 \%$ ) with longer follow up. Prediction of likely response may be helped by isotope investigation of the site of platelet sequestration presplenectomy, results being better in those in whom the spleen was shown to be the major site of consumption..$^{20}$ However, this investigation is not yet widely available and needs further validation. Splenectomy is associated with a small but life long increased risk of serious sepsis despite pneumococcal vaccination and penicillin prophylaxis. ${ }^{21}$ Children with chronic ITP and serious continuing bleeding are very rare indeed (estimated at one in 2.5 million per year), and should be referred to an experienced specialist. ${ }^{1}$

\section{Controversies in management}

A national audit of the management of acute childhood ITP was undertaken in 1995-96 against guidelines published in the UK in $1992^{19}$; it confirmed that acute ITP is a benign condition in most children. Over a 14 month period data were collected for 427 children. Although $82 \%$ had platelet counts less than 20 $\times 10^{9} / 1$, the majority were classified as clinically mild by their physicians $(73 \%$ of children with counts less than $\left.10 \times 10^{9} / 1\right)$. Only 13 children had severe bleeding manifestations (usually epistaxis or gastrointestinal haemorrhage); there were no intracranial bleeds or deaths. The audit showed very variable management (not related to the age or symptoms) - many children $(61 \%)$ were treated on the basis of a low count with steroids or IVIG. ${ }^{8}$ This variable practice has been noted independently, and with some anxiety, by the patient group (ITP support association). The audit is being repeated (January to December 2000) to see whether practice has changed as a result of publication and dissemination of the findings.

Many UK paediatric haematologists consider that most children with acute ITP do not need active treatment, which is in contrast to a practice guideline in the USA. ${ }^{7}$ The difficulty is with the evidence-there are insufficient well conducted randomised trials on which to base decision making. In addition, the trials have used platelet count as the end point rather than any clinical parameters. Clearly treatment can produce a rise in the platelet count, but at a cost to the child. Is there any clinical benefit? One recent survey of the few with more serious haemorrhage in ITP noted that treatment raised the platelet count by the next day only in a minority. ${ }^{22}$ Children given high dose steroids often exhibit behaviour disturbances and insomnia that can be hard to manage. If steroids have been started for a low count alone, it is difficult to continue their withdrawal in the face of a falling platelet count. IVIG is toxic, expensive, and invasive and most children would rather not have a drip. It is not clear whether the clinical outcome (as opposed to the platelet count) is different. The contrasting styles of management and strong views with which both are held clearly indicate the need for a large study of clinical outcome rather than platelet count alone, and including a "no treatment" arm in children with mild bleeding symptoms. Interestingly, $68 \%$ of American paediatric haematologists indicated their willingness to participate in such trials despite the fact that only $16 \%$ would currently not treat 
such a child. ${ }^{9}$ A quality of life indicator of some kind is also required, as the restrictions (variable) placed on a child's activity, especially if prolonged, and if a contact sport enthusiast, may also cause distress.

Life threatening or serious bleeding is fortunately rare, but should be treated promptly with IVIG, steroids, and platelet transfusions in larger than normal doses. Apart from this, platelet transfusions are not indicated in ITP, which is a consumptive platelet disorder. It was disappointing in the national audit to find platelets being transfused for clinically mild acute ITP (sometimes on the advice of haematologists).

\section{Chronic ITP}

About $10-20 \%$ of children will fail to remit over six months (chronic ITP). This is more likely in older children, especially adolescent girls. Underlying diseases may be present (for example, systemic lupus erythematosus) and should be sought. Many of these children do not run into significant bleeding problems and require no regular treatment. Such families need help and sensible advice concerning living with the disorder rather than a series of potentially toxic treatments which may do more harm than good. ${ }^{13}$ Splenectomy should be reserved for those who have both chronic ITP and significant bleeding problems ${ }^{23} ; 30 \%$ or more may relapse after splenectomy (see above). Long term follow up of children with chronic ITP has shown that remissions continue to occur over a prolonged period even 10 years after diagnosis (predicted spontaneous remission rate $61 \%$ after 15 years, ${ }^{24}$ similar to a $63 \%$ remission in another series ${ }^{23}$ ). Many individuals who do not remit, nevertheless run a chronic course with moderate rather than severe thrombocytopenia (by platelet count) and no significant symptoms. Most can live with their bruising and few limitations; treatment is appropriate for surgical interventions and accidents, and such children should carry a card or bracelet with information to this effect.

Additional useful information is becoming available via an intercontinental registry for childhood ITP (information can be obtained from the author or from the website at www.unibas.ch/itpbasel and has been presented in abstract form ${ }^{25}$ ). More than 2000 children have been registered from 42 countries with follow up information at six months in $68 \%$. A splenectomy registry has opened which has more than 70 children so far, and clinicians are encouraged to report the rare instances of intracranial haemorrhage. Collection of such information on an international basis is likely to help understand the natural history and complications of this usually benign disease.
1 Lilleyman JS. Management of childhood idiopathic thrombocytopenic purpura. Br f Haematol 1999;105:871-5.

2 Taub JW, Warrier I, Holtkamp C, Beardsley DS, Lusher JM. Characterization of autoantibodies against the platelet glycoprotein antigens IIb/IIIa in childhood idiopathic thrombocytopenia purpura. Am f Hematol 1995;48:104-7.

3 Donner M, Holmberg L, Nilsson I. Type IIB von Willebrand's disease with probable autosomal recessive inheritance and presenting as throm

4 Manco-Johnson MJ, Nuss R, Key N, et al. Lupus anticoagulant and protein $\mathrm{S}$ deficiency in children with postvaricella purpura fulminans or thrombosis. F Pediatr 1996;128:31923.

5 Halperin DS, Doyle JJ. Is bone marrow examination ustified in idiopathic thrombocytopenic purpura? Am $\mathcal{F}$ Dis Child 1988;142:508-11.

6 Calpin C, Dick P, Poon A, Feldman W. Is bone marrow aspiration needed in acute childhood idiopathic thrombocytopenic purpura to rule out leukemia? Arch Pediatr Adolesc Med 1998;152:345-7.

7 George JN, Woolf SH, Raskob GE, et al. Idiopathic thrombocytopenic purpura: a practice guideline developed by explicit methods for the American Society of Hematology. Blood 1996;88:3-40.

8 Bolton-Maggs PH, Moon I. Assessment of UK practice for Bolton-Maggs PH, Moon I. Assessment of UK practice for
management of acute childhood idiopathic thrombocytopenic purpura against published guidelines. Lancet 1997; penic purpura

9 Vesely S, Buchanan G, Cohen A, Raskob G, George J. Self reported diagnostic and management strategies in childhood idiopathic thrombocytopenic purpura: results of a survey of practicing pediatric hematology-oncology specialists. $\mathcal{F}$ Pediatr Hematol Oncol 2000;22:55-61.

10 Zipursky A, Poon A, Doyle J. Leukemia in Down syndrome: review. Pediatr Hematol Oncol 1992;9:139-49.

11 Imbach P, Berchtold W, Hirt A, et al. Intravenous immunoglobulin versus oral corticosteroids in acute immune thrombocytopenic purpura in childhood. Lancet 1985;ii:464-8.

12 Lilleyman JS. Intracranial haemorrhage in idiopathic thrombocytopenic purpura. Paediatric Haematology Forum of the British Society for Haematology. Arch Dis Child 1994;71:251-3.

13 Chessells J. Chronic idiopathic thrombocytopenic purpura: primum non nocere. Arch Dis Child 1989;64:1326-8.

4 Tarantino MD, Madden RM, Fennewald DL, Patel CC, Bertolone SJ. Treatment of childhood acute immune thrombocytopenic purpura with anti-D immune globulin or pooled immune globulin. F Pediatr 1999;134:21-6.

15 Blanchette V, Imbach P, Andrew M, et al. Randomised trial of intravenous immunoglobulin $G$, intravenous anti-D, and oral prednisone in childhood acute immune thrombocytooral prednisone in childhood acute imm
penic purpura. Lancet 1994;344:703-7.

penic purpura. Lancet 1994;344:703-7.
16 Warrier I, Bussel JB, Valdez L, Barbosa J, Beardsley DS. Safety and efficacy of low-dose intravenous immune globulin (IVIG) treatment for infants and children with immune thrombocytopenic purpura. Low-Dose IVIG Study Group. f Pediatr Hematol Oncol 1997;19:197-201.

17 Carcao MD, Zipursky A, Butchart S, Leaker M, Blanchette VS. Short-course oral prednisone therapy in children presenting with acute immune thrombocytopenic purpura (ITP). Acta Paediatr Suppl 1998;424:71-4.

18 Gaines A. Acute onset hemoglobinemia and/or hemoglobinuria and sequelae following $\mathrm{Rh}_{\mathrm{o}}$ (D) immune globulin intravenous administration in immune thrombocytopenic intravenous administration in immune thro

19 Eden OB, Lilleyman JS. Guidelines for management of idiopathic thrombocytopenic purpura. The British Paediatric Haematology Group. Arch Dis Child 1992;67:1056-8.

20 Najean Y, Rain JD, Billotey C. The site of destruction of autologous ${ }^{111}$ In-labelled platelets and the efficiency of splenectomy in children and adults with idiopathic thrombocytopenic purpura: a study of 578 patients with 268 splenectomies. Br f Haematol 1997;97:547-50.

21 Waghorn D, Mayon-White R. A study of 42 episodes of overwhelming post-splenectomy infection: is guidance for asplenic individuals being followed? F Infect 1997;35:28994.

22 Medeiros D, Buchanan GR. Major hemorrhage in children with idiopathic thrombocytopenic purpura: immediate with idiopathic thrombocytopenic purpura: immediate
response to therapy and long-term outcome. $f$ Pediatr 1998;133:334-9.

23 Tamary H, Kaplinsky C, Levy I, et al. Chronic childhood idiopathic thrombocytopenia purpura: long-term followidiopathic thrombocytopenia purpu
up. Acta Paediatr 1994;83:931-4.

24 Reid MM. Chronic idiopathic thrombocytopenic purpura: incidence, treatment, and outcome. Arch Dis Child 1995;72:125-8

25 Kuhne T. Intercontinental childhood ITP registry. Med Ped Oncol 1999;33:187. 